ANNALES

UNIVERSITATIS MARIAE CURIE-SKŁODOWSKA

LUBLIN - POLONIA

VOL. LXVII, 1-2

SECTIO AA

2012

\title{
The use of chromatographic and spectroscopic (colometric) methods \\ for evaluation of quercetine in dietary supplements of plant origin
}

\author{
Małgorzata Kostecka \\ Department of Chemistry, University of Life Sciences in Lublin, \\ ul. Akademicka 15, 20-950 Lublin, tel. (+48-81) 44568 46, julka-portal@wp.pl
}

\begin{abstract}
Recent years have witnessed a rapid increase in demand for dietary supplements which can be purchased over the counter and without medical consultation. They are widely advertised as panacea for all ailments that afflict the contemporary consumer. Products containing extracts from native and tropical plants as well as herbs have a growing share of the supplement market.

TLC is a simple and inexpensive method that can be used in preliminary analyses of product quality. Thin layer chromatography is also an effective technique for isolating biologically active substances from complex pharmaceutical products and supplements. Quantitative analysis shows that quantitative and qualitative inaccuracies and misstatements may occur in the case of dietary supplements.
\end{abstract}

\section{INTRODUCTION}

The interest in dietary supplements of plant origin and their health benefits has increased considerably in recent years. Plant-source foods and supplements are a source of unique ingredients which are essential for metabolic processes in the human body. Many of them have antioxidant properties, and they neutralize reactive oxygen species (ROS) (Ismail [1], Bray [2]) which are generated during biochemical transformations. 
Excessive levels of ROS can damage biological membranes and genetic material of cells (Grassi [3], Harborne [4], Havsteen [5]). Flavonoids are natural antioxidants which should be supplied with food (Hollman [6], Kim [7], Majewska [8]). Quercetin is a flavonoid which is widely distributed in nature, and has broad spectrum of activity:

- it reduces vascular permeability and seals up their walls,

- it has anticoagulant and anti-inflammatory properties,

- it acts as a natural antihistamine,

- it controls lipid concentrations in the bloodstream, it prevents oxidation of LDL cholesterol in the blood plasma,

- it increases maximal oxygen consumption $\left(\mathrm{VO}_{2} \max \right)$,

- it is an antioxidant and a free radical scavenger,

- it reduces fatigue and alleviates stress (Manach [9], Aherne [10], Olszewska [11], Yao [12]).

Quercetin also shows antimicrobial activity against Staphylococcus aureus, Pseudomonas aeruginosa and Klebsiella pneumoniae [13]. Quercetin restricts the proliferation of various neoplastic cells in the human body by blocking mutated oncogenes (p53, Ras) and inhibiting the cell division cycle (Gurib-Fakim[13]). The discussed flavonoid is also an anti-diabetic agent which inhibits 11b-HSD1 (11b-hydroxysteroid dehydrogenase), an enzyme specific for corticosteroid drugs which restrict insulin activity. The above mechanism increases blood glucose levels.

An unbalanced diet does not supply the required amounts of healthpromoting compounds, and the growing incidence of lifestyle diseases prompts the search for new dietary solutions. One of them are dietary supplements which are widely available in pharmacies, herb shops, drug stores and online shops. In view of the growing popularity of supplements containing flavonoids (quercetin, lutein, anthocyanidin), the content of the above compounds and their consumption levels should be investigated in greater detail (Miller[14]).

The European Union and Poland are working on new laws which will define the types of plant material that may be used in dietary supplements and their safe doses which deliver the desired physiological effects without harmful consequences. Dietary supplements are classified as food products, therefore they do not have to fulfill the requirements set for pharmaceutical drugs.

The properties of plant-source ingredients in dietary supplements may differ considerably, and some compounds may produce harmful 
effects when consumed in excessive amounts. The qualitative composition of dietary supplements should be monitored more rigorously to guarantee their safety for consumers.

Thin layer chromatography (TLC) is a popular analytical tool which is increasingly often used in conjunction with other techniques (Marston[15]). Estrada et al. used TLC to identify saponins in Polygala senega roots, and the profile of saponin fractions was further investigated by high-performance liquid chromatography (HPLC) [16]. TLC has a number of advantages over HPLC. TLC is performed with the use of disposable plates, therefore, material samples do not have to be highly purified, whereas in HPLC, impurities can lower the separation efficiency of the stationary phase. TLC supports simultaneous analyses, TLC plates can be stored for further use and the method contributes to greater detection accuracy. TLC is one of the key techniques used by the European Pharmacopoeia in analyses of plant material quality [17]. TLC also supports quick evaluations of the qualitative composition of compounds and dietary supplements.

\section{EXPERIMENTAL}

\section{Qualitative analysis of quercetin in dietary supplements}

The experimental material consisted of dietary supplements available in pharmacies and on the non-pharmacy OTC market in Poland. Ten products claimed to support weight loss and boost natural immunity were selected for the study. They were chosen in view of their popularity based on the results of a consumer survey carried out in May 2011.

Quercetin was analyzed in aqueous and octane solutions. Dietary supplements were dissolved in water and in acetic acid to produce analytical samples of $0.12 \mathrm{mg} / 3 \mathrm{~cm}^{3}$ of solution. Chromatographic plates were covered with silica gel $\left(\mathrm{SiO}_{2}\right)$ (Merck), Kieselgel 60 F 254, DC Fertigplatten, $0.25 \mathrm{~mm}$. The mobile phase was toluene : isopropyl ether : formic acid (8:12:1). Quercetin $\left(\mathrm{C}_{15} \mathrm{H}_{10} \mathrm{O}_{7} \cdot 2 \mathrm{H}_{2} \mathrm{O}\right)$ (Sigma) was used as a reference standard.

Solutions of dietary supplements and the standard solution were applied to chromatographic plates with a Hamilton microsyringe to produce $2 \mathrm{~mm}$ spots. Chromatograms were developed in a chromatographic chamber. They were analyzed under UV light at $365 \mathrm{~nm}$ wavelength with the use of the following reagents: $1 \% \mathrm{FeCl}_{3} /$ methanol solution and $1 \% \mathrm{AlCl}_{3} /$ methanol solution. The presence of quercetin was 
determined based on the values of retention factor $\mathrm{Rf}$ relative to the standard.

\section{Quantitative analysis of quercetin by the colorimetric method}

Quercetin content was determined by the method proposed by (Lamaison and Carnat [18]). $1 \mathrm{ml}$ of $2 \% \mathrm{AlCl}_{3} \cdot 6 \mathrm{H}_{2} \mathrm{O} /$ methanol solution was added to $1 \mathrm{ml}$ of quercetin/methanol solution $\left(0.04 \mathrm{mg} / \mathrm{cm}^{3}\right)$. Absorbance was measured after 1 minute at $430 \mathrm{~nm}$ wavelength. Quercetin content was calculated from a calibration curve of quercetin.

Preparation of solutions:

$2 \% \mathrm{AlCl}_{3}$

$2 \mathrm{~g} \mathrm{AlCl}_{3} \cdot 6 \mathrm{H} 2 \mathrm{O}$ was dissolved in $100 \mathrm{~cm}^{3} 5 \%$ acetic acid solution in methanol.

\section{$5 \% \mathrm{CH}_{3} \mathrm{COOH}$ in $\mathrm{CH}_{3} \underline{\mathrm{OH}}$}

$9.6 \mathrm{~cm}^{3}$ of $98 \% \mathrm{CH}_{3} \mathrm{COOH}$ was measured, and dissolved in $200 \mathrm{~cm}^{3}$ of methanol

Mixture I

$\mathrm{CH}_{3} \mathrm{COOC}_{2} \mathrm{H}_{5}: \mathrm{CH}_{3} \mathrm{COOH}: \mathrm{CH}_{3} \mathrm{OH}=40: 3: 57$

Preparation of calibration curve:

Methanol solution of known quercetin concentration was used for calibration $\left(0.025 \mathrm{mg} / 1 \mathrm{~cm}^{3}\right)$. Into flasks of $50 \mathrm{~cm}^{3}$ were measured successively from $0.50,1.0,1.5,2.0$, to $20.0 \mathrm{~cm}^{3}$ of prepared solution of quercetin. $2 \mathrm{~cm}^{3}$ of a solution $2 \% \mathrm{AlCl}_{3}$ and mixture I were added to each flask.

\section{RESULTS AND DISCUSSION}

A qualitative analysis of the investigated compounds confirmed that the qualitative and quantitative composition of commercially available dietary supplements is often incorrect. The results of TLC revealed that not all examined supplements contained quercetin (Table 1). Yellow fluorescent spectra of quercetin spots were observed on chromatographic plates at $365 \mathrm{~nm}$ wavelength. The studied flavonoid was successfully separated by the applied eluent, and it was identified based on the calculated value of $\mathrm{Rf}$. 
The majority of supplements with inaccurate composition data were manufactured by small local suppliers who are not subject to pharmaceutical supervision. The above poses a significant risk because consumers look to dietary supplements as safe products which supply biologically active substances in amounts declared by their anufacturers. False or incorrect data may be misleading for consumers, and substances which are not listed or whose amounts are underestimated may cause dangerous interactions with food products or medications.

TLC is a simple and inexpensive method that can be used in preliminary analyses of product quality. At successive stages of the evaluation process, dietary supplements can be subjected to qualitative analyses with the involvement of HPLC or other spectroscopic methods. In this experiment, dietary supplements were analyzed by colorimetric methods, which is a simple and inexpensive technique.

Table 1. Quercetin content in 1 capsule/tablet and in the recommended daily intake of the analyzed dietary supplements.

\begin{tabular}{lccc}
\hline \multicolumn{1}{c}{ Supplement } & $\begin{array}{c}\text { Quercetin } \\
\text { content in 1 } \\
\text { capsule/tablet, } \\
\text { in our } \\
\text { investigations }\end{array}$ & $\begin{array}{c}\text { Recommended } \\
\text { daily intake }\end{array}$ & $\begin{array}{c}\text { Quercetin } \\
\text { content in } \\
\text { recommended } \\
\text { concentration }\end{array}$ \\
\hline Linea Detox & $35 \mathrm{mg}$ & 2 tablets & $35 \mathrm{mg}$ \\
Rutimal C & not found & 1 capsule & $20 \mathrm{mg}$ \\
Cidrex & $12 \mathrm{mg}$ & 2 tablets & $10 \mathrm{mg}$ \\
CLA and green tea, & $59 \mathrm{mg}$ & 4 capsules & $50 \mathrm{mg}$ \\
Teavera, & not found & 2 capsules & $30 \mathrm{mg}$ \\
CLA and green tea, & $45 \mathrm{mg}$ & 6 capsules & $40 \mathrm{mg}$ \\
Teafil Detoxica, & not found & 1 capsule & $15 \mathrm{mg}$ \\
Quercetin+vitamin C & $340 \mathrm{mg}$ & 1 capsule & $500 \mathrm{mg}$ \\
Alercal (Zdrovit) & $110 \mathrm{mg}$ & 1 tablet & $120 \mathrm{mg}$ \\
calcium + quercetin & & 1 tablet & $60 \mathrm{mg}$ \\
Calcium Alergo & $54 \mathrm{mg}$ & & \\
Plus, & & &
\end{tabular}

The results of HPLC confirmed the findings of the TLC analysis. The quantitative composition of quercetin in the examined supplements did not differ significantly from the declared content, $\pm 5 \%$. The only 
exception was Quercetin + Vitamin C, where the active substance content was determined at $68 \%$ of the declared value.

Thin layer chromatography is also an effective technique for isolating biologically active substances from complex pharmaceutical products and dietary supplements. Hachuła et al. relied on TLC to isolate vitamin C [19], whereas Wiergowski et al. used the discussed method to confirm the presence of sibutramine hydrochloride in a herbal supplement based on the value of retention factor Rf [20]. TLC has been increasingly often used by research centers around the world to isolate and separate phenolic acids and complex flavone derivatives from plant material (Fecka 21], Gleńsk [22] and Smolarz [23]). The selection of an appropriate mobile phase supports the separation of active substances even from highly complex compounds.

\section{CONCLUSIONS}

1. Thin layer chromatography is a highly useful analytical instrument for evaluating the quality of pharmaceutical products and dietary supplements containing bioactive substances of plant origin.

2. The selection of an appropriate mobile phase in TLC supports the separation of complex polyphenolic compounds isolated from plant material.

3. Dietary supplements should be subjected to more rigorous qualitative and quantitative control to eliminate false and inaccurate claims regarding their composition.

\section{REFERENCES}

[1] A. Ismail, Z. Marjan and C.W. Foong, Food Chem., 87, 581, (2004).

[2] T.M. Bray, Nutrition, 16, 578, (2000).

[3] D. Grassi, G. Desideri and C. Ferri, Nutritients, 2, 889, (2010).

[4] J.B. Harborne, C.A. Williams, Phytochem., 55, 481, (2000).

[5] B.H. Havsteen, Pharmacol. Ther., 96(2-3) 67, (2002).

[6] P.C. Hollman, M.B. Katan, Food Chem. Toxicol., 37, 937, (1999),

[7] H.P. Kim, K.H. Son and H.W. Chang, J. Pharmacol. Sci., 96, 229, (2004),

[8] M. Majewska, H. Czeczot, Farm. Pol., 65, 369, (2009). 
[9] C. Manach, A. Scalbert and C. Morand, Am. J. Clin. Nutr., 79, 727, (2004).

[10] S. A. Aherne, N.M. O'Brien, Nutrition, 18, 75, (2002).

[11] M. Olszewska, Farm. Pol., 59, 391, (2003).

[12] L. H. Yao, Y. M. Jiang and J. Shi, Plant Foods Hum. Nutr., 59, 113, (2004),

[13] A. Gurib-Fakim, Mol. Aspect. Med., 27, 1, (2006).

[14] E. Miller, K. Malinowska and E. Gałęcka, Pol. Merk. Lek., 144, 556, (2008).

[15] A. Marston, Phytochem., 68, 2785, (2007).

[16] A. Estrada, G. S. Katselis, Comp. immunol. microb., 23, 27, (2000).

[17] S. Apers, T. Naessens, J. Chromatogr. A., 1112, 165, (2006).

[18] J. L. C. Lamaison, A. Carnet, Pharm. Acta. Helv., 65, 315, (1990).

[19] U. Hachuła, B. Zawisz and W. Winkler, Roczniki PZH, 51, 71, (2000).

[20] M. Wiergowski, K. Galer-Tatarowicz, Przeglad Lekarski, 64, 268, (2007).

[21] I. Fecka, W. Cisowski and M. Łuczkiewicz, J. Planar Chromatogr., 14, 405, (2001).

[22] M. Gleńsk, U. Sawicka, J. Planar Chromatogr., 15, 463, (2002).

[23] H. D. Smolarz, E. Medyńska and G. Matysik, J. Planar Chromatogr., 18, 319, (2005). 